\title{
The impact of the bonus at birth on reproductive behaviour in a lowest-low fertility context: Friuli-Venezia Giulia (Italy), 1989-2005
}

\author{
Giovanna Boccuzzo, Marcantonio Caltabiano, Gianpiero Dalla Zuanna, \\ and Marzia Loghi*
}

\begin{abstract}
As of 1 January 2000 the government of the north-eastern Italian region of FriuliVenezia Giulia (FVG) introduced a substantial bonus at birth. The birth bonus was differentiated by marital status (only married women were eligible), citizenship (only Italians were eligible), and birth order (the bonus grew for the second and especially the third birth). Moreover, the income threshold below which one got the bonus was fairly high. As of 1 January 2004 a new government substantially reduced the bonus amount as well as the upper income limit. We evaluate if the bonuses handed out in FVG during those four years (2000-03) had a significant impact on fertility and abortion choices, verifying whether fertility changed in a different way for women more affected by the new legislation. We also test if the impact of monetary measures was higher for less educated women, because in Italy the relationship between income and education is very strong, and the bonus was practically the same irrespective of income level, hence its relative impact should be stronger in a poorer family. We use two different methods: First, we compare the trends of births and abortion ratios, separately for women affected and not affected by the monetary measures, looking at the differential changes. Second, using log-linear models, we measure if the interactions among time, parity, marital status, citizenship and education are statistically significant in the direction that follows our expectations. Our results show that for low educated (and hence also less rich) women with one or (especially) two and more children, birth trends did change after 1999, whereas the trends for childless women living in FVG and for low-educated women living in other Italian regions did not change.
\end{abstract}

\footnotetext{
* Giovanna Boccuzzo (author of correspondence), Department of Statistical Sciences, University of Padua, via C.Battisti 241, 35121 Padua, Italy. Email: boccuzzo@stat.unipd.it

Marcantonio Caltabiano, Department of Economics, Statistics, Mathematics and Sociology, University of Messina, Messina, Italy.

Gianpiero Dalla Zuanna, Department of Statistical Sciences, University of Padua, Padua, Italy.

Marzia Loghi, Istat - Italian National Statistical Institute, Rome, Italy.
} 


\section{Introduction}

There appears to be general scepticism in the literature over whether public policies have an impact on choices concerning fertility. For instance, in a detailed overview of the influence policies have on birth rates, Gauthier (2007) stated that

"[o]verall, thus, the multivariate studies provide mixed conclusions as to the effect of policies on demographic and economic behaviour, once other factors such as education, income, etc. are 'controlled' for. The effect-if any-tends moreover to be small. Methodological issues may be at the basis of these inconclusive findings ..." (see also Gauthier 2004).

These results are substantially confirmed by a recent econometric analysis (Kalwij 2008).

On the other hand, scholars have shown that in Italy-from 1999 on-some monetary allowances aimed at poor couples with three or more children below age 18 have significantly increased the parity progression ratio from second to third birth for poor women, and have decreased the abortion ratio for women with two children in the same group (Billari et al. 2005). In the present paper we further investigate this issue, employing a similar methodological and substantive approach. More specifically, we consider the north-eastern Italian region of Friuli-Venezia Giulia (FVG, population of 1.2 million at the beginning of 2008), where despite extremely low fertility rates over the last 30 years (the period total fertility rate, TFR, was below 1.5 from 1978 onward and fell below 1.2 in 19922003) there are now some signs of recovery (the TFR reached 1.3 in 2007). Since FVG is one of the six autonomous Italian regions - and as such has greater political and fiscal autonomy - the region has been able to develop strong family policies, reinforcing national legislation. From 2000-03 FVG implemented a particularly generous bonus at birth for women with one or more children.

The statistical techniques employed aim at isolating the effect of the bonus on reproductive and abortive behaviour, and not at explaining the causes of lowestlow fertility in Italy in general or in FVG alone. Research conducted on the latter issue has suggested a number of causes for the very low birth rates. These include insufficient compatibility between female participation in the labour force and fertility, in part a consequence of an ungenerous welfare system towards families with children (Bettio and Villa 1998; Salvini 2004). Scholars have also pointed out the high degree of gender inequality within the family, which often sees the woman take on a heavy workload, especially if she is not a housewife but has a job as well (McDonald 2000; Mills et al. 2008). Yet others have underlined the excessive amount of responsibility parents feel for the social status of their children (Livi Bacci 2001; Dalla Zuanna 2001). Finally, over the course of the 1980s and 1990s, increasing secularism (implying a diminishing influence of the Catholic church on Italians' personal choices) may have played a role in the particularly dramatic decline of fertility in FVG and in Italy more generally (Dalla Zuanna and Righi 1999). 
Over the last twenty years, the economy of FVG has thrived and unemployment has been practically inexistent. This has been accompanied by high levels of foreign immigration into the region and an income growth rate on average higher than that of the nation, and in line with the richer and more dynamic regions of Europe. Widespread wealth and continuous growth, however, have not prevented certain groups of people from limiting their fertility for economic reasons. For example, at the end of 2001, representative samples of mothers aged about 42, living in five Italian cities (including Udine, the second largest city in FVG, population of 100,000 in 2007) were asked about their motivations for not having another child (De Santis and Breschi 2003). Two of these motivations were directly linked to economic matters ("It was too expensive to have another child" and "Another child would have damaged the economic well-being of the children I already have"). Both reasons saw a gradient by education. In particular, $63 \%$ and $44 \%$ of low educated women with two or more children agreed to the two statements, respectively, compared to $23 \%$ and $16 \%$ among high educated women with two or more children. This is most likely not a problem of education, but the results rather mirror the 'income effect': in Italy education and income are strongly related. In 2000, the mean income of a man aged 30-44 with less than an upper secondary education was $72 \%$ of that of his age-mates with an upper secondary education (the same proportion was $86-87 \%$ in France, Sweden, the Netherlands, and Germany, OECD 2004, Table A11.1a). Consequently, the bonus at birth may have pushed the less rich and/or less educated couples to change their reproductive choices - an issue we intend to explore in this article.

In Boccuzzo et al. (2008), we illustrate in detail the monetary policies adopted by FVG from 1989 to 2007 . For the sake of our present objective it is particularly important to highlight changes which occurred between 1 January 2000 and 1 January 2004, when the regional government introduced substantial bonuses at birth. These were much more generous and targeted to more specific groups than the policies adopted in the years which preceded and followed that period. In addition, the bonuses were based on several prerequisites: marital status (only married women eligible), citizenship (only couples with at least one Italian or EU partner eligible), and parity (no bonus for first births; $€ 3,000$ for second births; $€ 4,600$ for third and subsequent births). The maximum income threshold below which one received the bonus was rather high: $€ 25,823$ for women with one child and $€ 46,481$ for women with two children or more. While not comparable with measures introduced in other European countries, this is - to the best of our knowledge - the strongest birth-related monetary policy ever implemented in Italy after World War Two. Since 1 January 2004, the new regional government has extended the bonus to include unmarried women and non-EU foreigners who have lived in FVG for at least five years, but both the amount paid out and the income threshold have been substantially reduced. 
If the bonus indeed did have an impact on fertility, the reproductive behaviour of Italian married women during the years 2001-04 in FVG should have changed, and we should find differences by parity and education. Our main expectation is that we will find different patterns of behaviour among women without children, those with only one, and especially, among those with two or more children. We also expect to find a stronger effect for less educated (proxies of less rich) people, both because the bonus was not given to wealthier couples, and mainly because the relative magnitude of the bonus is higher the lesser the income. In addition, we should see no change among non-married couples and foreign families, as they were not eligible for the bonus. Finally, the behaviour of women living in FVG should diverge from that of women living in all other Italian regions, where no additional monetary family policies were implemented.

In the following sections, we describe our data (Part 2) and methods (Part 3). In Part 4, we present the main results. Part 5 gives an overview of the results and their political relevance. The appendix shows the original data before and after the imputation of missing values.

\section{Data}

Data on births classified by mother's education, parity, marital status, and citizenship were kindly provided by the Public Regional Health Administration of FVG (for 1989-2005). The source of births is the certificate of delivery care (CEDAP), adopted at the national level only in 2002 but available for previous years as well in FVG. The CEDAPs contain demographic and social variables about both parents, information concerning the pregnancy and the delivery, as well as the health of the newborn. The CEDAP file we dealt with did not have any data missing. Legal abortions for the years 1989-2005, classified by mother's education, parity, marital status, and citizenship were kindly made available by the National Institute of Statistics (Istat). The data source with regard to abortions is an anonymous form for induced abortion, filled out at the hospital for each intervention and sent to the ISTAT. The form includes some information on woman (age, education, marital status, parity and citizenship) as well as some characteristics of the abortion. The coding of educational level was missing in some of the original data on abortions for years 1999, 2000 and 2001. These were redistributed in accordance with the known data distribution (see Appendix). The birth series from CEDAP of FVG were compared to the corresponding series of population registers, which showed only negligible differences.

Unfortunately, as only a few other regions have such long-term series data, the CEDAP data cannot be used to compare trends in births between FVG and the rest of Italy. We therefore estimate the overall birth trends by women's parity and education in Italy using data from the most recent ISTAT survey on women's reproductive behaviour. The survey, entitled "Famiglia e Soggetti Sociali" 
(Multipurpose Survey of Families) was carried out in 2003 and consists of interviews with a representative sample of 49,541 individuals belonging to 19,227 families. For our analysis we selected those women in the sample who were married at the time of birth of their child(ren) and were not residents in FVG. The sample obtained is representative of Italy as a whole, not including FVG. These data were not used for the region of FVG because the number of observations is too small. We therefore resorted to the CEDAP data.

We then aggregated all births from these women according to birth order and the mother's education (high vs. low) at the birth of each child for the years 19892003, weighting each birth with the respective sample weight of the mother. Finally, using these time-series we estimated the index numbers of births (with the base in $1989=100$ ) and compared them to those from the FVG series. It would have been preferable to compare the FVG data with those estimated for northern Italy only, as the two areas are more similar from the socio-economic viewpoint, but unfortunately due to the limited sample size this was impossible.

\section{Methods}

We measure whether fertility behaviour changed in FVG during 2001-04 for those women most directly affected by the new legislation (Italian married women with one or more children). As already described in the introductory section, we assume that the impact of monetary measures was higher for less educated women given that (1) in Italy the relationship between income and education is very strong (the lower the education, the lower the income) and (2), that the amount of the bonus, given within a relatively high threshold of eligibility, was fixed (not dependent on income); consequently, its relative impact should be stronger in poorer families. Figure 1 shows the hypothetical relationships between bonus at birth and demographic events. In order to reliably test the causal relationship between the bonus at birth and individual reproductive decisions, one would have to compare the behaviour of those who received the bonus and those who, although otherwise very similar, were not eligible for the bonus. However, the data needed to draw this comparison are not available because when FVG put the policy into practice, no effort was made to provide the statistical instruments necessary for evaluating the effects such policies had on the reproductive behaviour and well-being of the families involved.

The remaining methodological possibility is to 'simulate' an experimental situation, using the available data. The idea is to identify different groups, distinguishing between them in terms of (1) their hypothetical eligibility for the bonus and (2) the hypothetical impact the former should have had on reproductive

\footnotetext{
The most famous example of demographic research conducted using an experimental framework is the Matlab Project (see e.g. Fauveau 1994; Samara et al. 1996).
} 
behaviour observed during the period in which the bonus was in force and in the preceding and following periods. If the groups most eligible for the bonus systematically modified their reproductive behaviour in the direction hypothesised (increase in the number of children and decrease in the number of abortions), and if no change were simultaneously observed among the other groups, than it is possible that the bonus indeed did have an impact.

\section{Figure 1:}

Hypothetical impact of the bonus at birth on women's reproductive behaviour

\section{FOR ELIGIBLE WOMEN}

(i.e., women with at least 1 child with low or medium income)

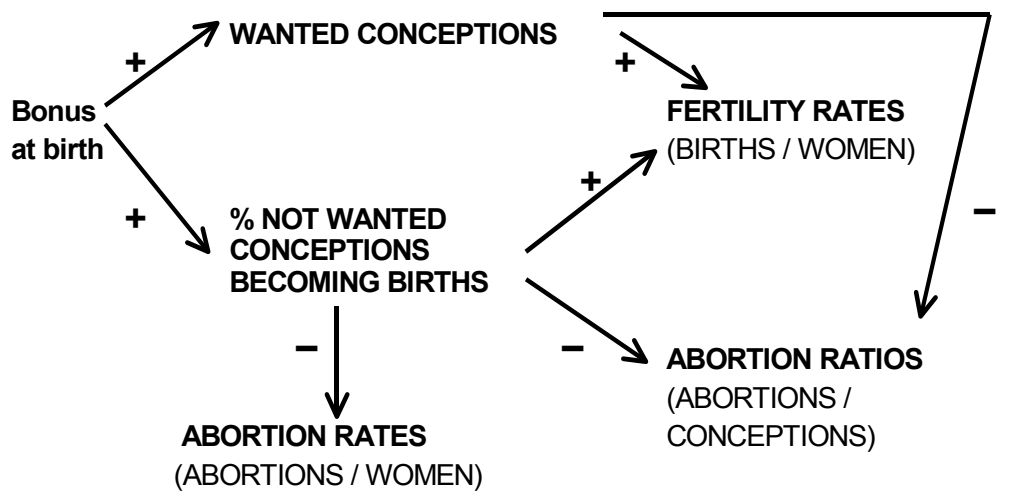

As mentioned above, our data allow us to identify the married women resident in FVG with low levels of education and two or more children as the most eligible and hypothetically most sensitive group to the bonus. The behaviour of these women is then compared with that of three other groups of FVG women who could have received the bonus but who would have received less money (women with one child) or for whom the bonus would comparatively have had less of an impact (women with higher levels of education). In addition, this comparison is extended to include FVG women without children, for whom (in the period considered) no bonus was foreseen for the birth of the first child. The other two groups that did not have a right to the bonus were foreigners and nonmarried couples. However, because both the dynamics of births out of wedlock and the behaviour of foreign couples are so erratic in the period under consideration, it is practically impossible to use graphical methods for mapping the gaps during 2001-2004 compared to the trend in the preceding period. These groups will instead be considered within the multivariate analysis presented in Section 3.2. Finally, six groups of FVG women are compared to analogous groups resident in other Italian regions. If the reproductive behaviour observed in FVG 
during the period in which the bonus was in effect was not repeated elsewhere (again, no other region had a comparable monetary policy supporting the national one) then the idea that a bonus had an impact on reproductive behaviour would be further strengthened.

The logic used is therefore of a difference-in-difference (DD) kind ${ }^{2}$ : we observe how differences in the number of children and abortions change among different groups during the periods in which the bonus was in effect and when it was not. These groups are identified on the basis of hypothetical eligibility and sensitivity to the bonus:

Hypothesis of the effect of the 2000-03 bonus on fertility

\begin{tabular}{ll|ccc}
\hline & Education & $\mathbf{0}$ & $\mathbf{1}$ & $\begin{array}{c}\text { 2 and } \\
\text { higher }\end{array}$ \\
\hline \begin{tabular}{ll|cc} 
Married Italian women \\
living in FVG
\end{tabular} & Low & $=$ & ++ & +++ \\
& High & $=$ & + & ++ \\
\hline $\begin{array}{l}\text { Married Italian women } \\
\text { NOT living in FVG }\end{array}$ & Low & $=$ & $=$ & $=$ \\
& High & $=$ & $=$ & $=$ \\
\hline \multicolumn{2}{l}{ Note: +++ Strong effect, ++ Medium effect, + Weak effect, $=$ No effect }
\end{tabular}

Following the DD framework, in order to confirm that the bonus did have an effect, observations of an increase in fertility among low educated married women living in FVG are not sufficient. We must also observe that non-eligible women did not change their reproductive behaviour.

The bonus was intended only for Italian couples with one child or more. However, it is possible that some couples, who were aware of the bonus but still without children, might have accelerated their fertility plans by rapidly having a first and then a second child. However, it is difficult to imagine this behaviour being widespread, given that the bonus policies changed too rapidly over time to effectively encourage couples to make long-term investments (Boccuzzo et al. 2008). On the other hand, as only married couples were eligible for the bonus, some may have felt the incentive to tie the knot.

As mentioned above, it was not possible to identify exactly the behaviour of those who could or could not receive the bonus. Consequently, no clear-cut causal reasoning can be applied to our analysis. Theoretically speaking, other unmeasured variables (e.g. ideational changes, gender equality, etc.) may have had a selective impact on some women, influencing their fertility trends. Our nonexperimental framework therefore provides only some insights as to the impact of

2 For a simple explanation of difference-in-difference rationale, see e.g. Angrist and Krueger (1999: 1296-1299). 
bonus. That said, our comparison between groups is wide enough (high parities vs. low parities, high education vs. low education, living in FVG vs. not living in FVG), that it is difficult to imagine that - if the previous framework fits our data - the bonus at birth might not have been significant.

\subsection{Graphical analysis}

To test - in a very simple way - the efficacy of the bonuses at birth implemented in the FVG region, we apply an analysis implemented earlier by Billari et al. (2005) in an analogous context.

We compare trends in births and abortion ratios [Abortions / (Abortions +Births)] in two different groups, one that includes the women hypothetically eligible for the above-described monetary policies and the other one made up of those women who were not eligible. More specifically, we compare, separately for the two groups, the number of events (or ratios) observed in years 2001-04 against the number of events (or ratios) that would be expected in the same years if the trend between 1989 and 2000 had continued unchanged (Figure 2 and Tables 1 and 2).

Then, we also evaluate the trend in births for married Italian women in FVG against the same trend for married women in Italy as a whole (excluding FVG), where the bonus at birth was not implemented (Figure 3).

In both comparisons the statistical significance of the difference between actual events and hypothetical ones is measured by comparing the angular coefficient of the line extrapolating the 1989-2000 trend with that of the line interpolating the actual pattern during the period of 2001-04.

\subsection{Multivariate analysis}

In the graphical analysis described above, the choice of years used to determine the temporal trend was conditioned by the available data. If the trend were determined on the basis of more (or fewer) years than the entire 1989-2000 interval, the results could change. In addition, trends in 1989-2000 may be influenced also by fluctuations of births and abortions due to several causes (e.g., changes in their timing). Finally, graphical analysis does not allow us to confidently determine the birth pattern over time among groups not eligible for the bonus (foreign women and/or not married) nor those most eligible (married Italian women with three or more children). In light of these obstacles, we use the same data for FVG to carry out a more refined analysis of the association between time and other variables, using log-linear (on births) and logistic (on abortion ratios) models.

Criteria of eligibility for the bonus are based on four variables: civil status, income (we approximate this using the level of education), citizenship, and parity. We want to measure how these variables interacted when the bonus was in force. 
For example, in the passage from the year 2000 to the following years, did the number of births among Italian women with two or more children increase? The log-linear model allows us to respond to this type of question, in that it decomposes the association between statistical variables, identifying their significant interactions.

Our log-linear model takes into consideration the following variables and conditions:

$\mathrm{X}=$ TIME: five periods corresponding to the main changes in family law: 1989-92, 1993-99, 2000, 2001-03, 2004-05 (i = 1, ..5).

$\mathrm{Y}=$ MARITAL STATUS: married, not married $(\mathrm{j}=1,2)$.

$\mathrm{Z}=E D U C A T I O N$ : low (up to middle school), high (high school or university) $(\mathrm{k}=1,2)^{3}$.

$\mathrm{W}=$ CITIZENSHIP: EU community, outside $\mathrm{EU}(\mathrm{h}=1,2)$

$\mathrm{T}=$ PARITY: $0,1,2,3+(\mathrm{m}=1, \ldots 4)$

As is evident, the level of detail is much greater than in the graphical analysis. In particular, by isolating the year 2000 and the period 2001-03, the effect of the bonus should emerge without further reference to the temporal trend. The categories of those who are more or less eligible for the bonus should also be more easily identifiable.

The log-linear model is represented as follows (Agresti 2002):

$\log \left(\mu_{i j k h m}\right)=\lambda+\lambda_{i}^{X}+\lambda_{j}^{Y}+\lambda_{k}^{Z}+\lambda_{h}^{W}+\lambda_{m}^{T}+\lambda_{i j}^{X Y}+\lambda_{i k}^{X Z}+\lambda_{j z}^{Y Z}+\ldots+\lambda_{i j k}^{X Y Z}+\ldots+\lambda_{i j k h}^{X Y Z W}+\ldots+\lambda_{i j k h m}^{X Y Z W}$

$\mu_{i j k h m}$ is the number of births in period $i$ from women with civil status $j$, level of education $k$, citizenship $h$, and parity $m$. In model (1), $\mu_{i j k h m}$ depends on an average general value $(\lambda)$, on time $X$ (through the principal effect $\lambda_{i}^{X}$ ), on civil status $\mathrm{Y}\left(\lambda_{j}^{Y}\right)$, on level of education $\mathrm{Z}\left(\lambda_{k}^{Z}\right)$ on citizenship $\mathrm{W}\left(\lambda_{h}^{W}\right)$, on parity $\mathrm{T}$ $\left(\lambda_{m}^{T}\right)$, and on the interactions of these five variables. Equation (1) defines the saturated log-linear model, because it includes all of the possible interactions between the five variables, both in pairs $\left(\lambda_{i j}^{X Y}, \lambda_{i k}^{X Z}, \lambda_{j k}^{Y Z}, \ldots\right)$ and at higher levels, up to the interactions between all five $\lambda_{i j k h m}^{X Y Z W T}$. The final model consists only of those parameters which were statistically significant. This includes several

The best split of the education levels related to income should be between high school and university, but the number of graduates is too low (see Appendix) to consider only this group versus the other three, because the analyses further divide the group in many sub-groups. Anyway, the adopted groups are nearly as efficient. 
parameters which are 'obviously' significant. For example, $\lambda_{j}^{Y}$ is the principal effect of civil status ( $\mathrm{i}=1$ married; $\mathrm{i}=2$ not married). Due to the fact that during the period 1989-2005 in the rest of Italy, like in FVG, there were a noticeably higher number of births from married women, the parameter $\lambda_{1}^{Y}$ relative to married individuals is positive and always significant. Analogously, the model contains significant interactions by virtue of population or fertility dynamics. For example, the interaction between time and citizenship $\lambda_{i h}^{X Z}$ will surely see $\lambda_{52}^{X Z}>\lambda_{12}^{X Z}$, because during time 5 (2004-05), as a consequence of continuous immigration, the number of births from non-European women was much higher compared to time 1 (1989-92).

In this analysis, we are interested only in those interactions which may indicate the effect of the bonus on reproductive behaviour, after controlling for all other significant conditions. Because the bonus was granted for such a short period of time, and only to Italian married women with less than a given income (which we approximated by way of the level of education) and with more than one child, we focus our attention on two higher-order interactions:

- $\lambda_{i j k m}^{X Y Z T}$ : interaction among time, marital status, education and parity

- $\lambda_{i j h m}^{X Y W T}$ : interaction among time, marital status, citizenship and parity

The bonus may have had an effect if significant statistical changes in $\lambda_{i j k m}^{X Y Z T}$ and $\lambda_{i j h m}^{X Y W T}$ are observed in the shift from period 3 (2000) to period 4 (2001-03). If the bonus worked, we should see $\lambda_{3114}^{X Y Z T}<\lambda_{4114}^{X Y Z T}$ (less educated married women of high parity having more children in 2001-03 than in 2000), whereas for the groups not affected by the bonus the differences between $\lambda_{3 j k m}^{X Y Z T}$ and $\lambda_{4 j k m}^{X Y Z T}$ should not be statistically significant. Analogously, we should see $\lambda_{3114}^{X Y W T}<\lambda_{4114}^{X Y W T}$ (married EU women of high parity having had more children during 2001-2003 than in 2000), whereas for the groups not affected by the bonus the difference between $\lambda_{4 j k m}^{X Y W T}$ and $\lambda_{3 j k m}^{X Y W T}$ should not be statistically significant either.

The strategy is to (a) estimate the model which best fits the data; (b) verify that the model includes interactions of interest to this project; and (c) verify if the interactions work in the direction hypothesised.

The procedure to select the 'best' model was employed as follows. First, the significant interactions were selected using a backward hierarchical approach: beginning with the saturated model, we excluded the non-significant interactions (CATMOD procedure using SAS). Second, using the model thus obtained, the excluded interactions were inserted one at a time in order to evaluate if - when 
considered individually - their specific contribution to the representation of the data was significant. We thus developed the final model which considers only the significant interactions, and therefore is no longer of a hierarchical nature (i.e. the presence in the model of a high-level interaction effect does not imply the presence of corresponding lower-level effects).

With regard to abortions, we used a logistic model (using the ratio of abortions to births as a dependent variable):

$$
\operatorname{logit}\left(\pi_{i j k h m}\right)=\log \frac{\pi_{i j k h m}}{1-\pi_{i j k h m}}=\alpha+\beta_{i}^{X}+\beta_{j}^{Y}+\beta_{k}^{Z}+\beta_{h}^{W}+\beta_{m}^{T}+\beta_{i j}^{X Y}+\ldots .+\beta_{i j k h m}^{X Y Z W T}
$$

where $\pi_{i j k h m}$ is the ratio of abortions to births corresponding to time $i$, civil status $j$, citizenship $h$, level of education $k$, and parity $m$. The parameters $\beta$ define the effect of the explanatory variables on ratio $\pi$. Compared to the log-linear model, the logistic model does not consider absolute numbers but rather relative numbers; hence the effects of the population structure are not present.

Analogous to the explanation above, we are interested above all in $\beta_{i j k m}^{X Y Z T}$ and $\beta_{i j h m}^{X Y W T}$, which become meaningful when we see a significant reduction in the parameters regarding married women with many children and low education or Italian citizenship in the shift from 2000 to the next period.

\section{Results}

\subsection{Graphical analysis}

We compare actual births and abortion ratios of married Italian women in FVG in 2001-04 with expected births and abortion ratios for the same women if the trend for 1989-2000 remained unchanged (Figure 2). We examine births to women specified by their parity status and education. The main results are as follows:

1. There is a remarkable divergence between birth trends and actual births in 2001-04 for women with two or more children, mostly attributable to women with low levels of education (who were supposedly more responsive to a bonus).

2. Conversely, there is no effect for low educated women with parity 0 and 1. Thus, the FVG fertility policy may have affected only poor women with access to the relatively largest bonus.

3. The changes were less intense for women with the highest levels of education, but here they also affected women who had only one child before.

4. Abortion ratios for low educated women decreased in 2001-04 mostly among those with two or more children, but also for women who already had one child. For high-educated women, changes took place only among those with parity two or higher. 
Finally, we compare the births to women with two or more children in FVG with those in the rest of Italy (Figure 3). The index numbers for low-educated women diverged noticeably after 2000: in FVG there was an upward divergence from the previous trend, whereas in the rest of Italy the previous decrease intensified. Differences for high-educated women with two or more children were less marked, although a slight increase in FVG could be observed, while generally in Italy the trend did not change.

In Table 1 we show the differences between the actual number of births recorded in 2001-04 and the birth trend projection from 1989-2000. The number of births increased for women with parity 1 and 2+, whereas it decreased for women without children. In Table 2, we compare observed abortion ratios with those expected according to the projections based on the 1989-2000 trend. Abortion ratios decreased for women with parity $2+$, especially for low-educated women but also for high-educated women. The differences diminished for women of parity 1 and disappeared for those of parity 0 .

Table 1:

Number of children by parity $(0,1,2+)$ and education (low, high) during 2001-04. Difference between actual numbers and projections from the 1989-2000 trend. Married Italian women living in FVG

\begin{tabular}{crrr}
\hline & \multicolumn{3}{c}{ Education } \\
Parity & Low & High & Total \\
\hline 0 & -650 & -422 & -1.072 \\
1 & +103 & +434 & 537 \\
$2+$ & +332 & +157 & 489 \\
\hline Total & -215 & 169 & -46 \\
\hline
\end{tabular}

Table 2:

Abortion ratios by parity (0, 1, 2+) and education (low, high) during 2001-04. Difference between actual ratios and projections from the 1989-2000 trend. Married Italian women living in FVG

\begin{tabular}{ccccccc}
\hline & \multicolumn{3}{c}{ Low education } & \multicolumn{3}{c}{$\begin{array}{c}\text { High education } \\
\text { Parity }\end{array}$} \\
\hline & 0 & 1 & $2+$ & 0 & 1 & $2+$ \\
2001 & 0 & -2 & -3 & 0 & 0 & -1 \\
2002 & 0 & -1 & -2 & 1 & 0 & -4 \\
2003 & 0 & -2 & -8 & 1 & -1 & -3 \\
2004 & 2 & 1 & -8 & 1 & 0 & -1 \\
\hline
\end{tabular}


Figure 2:

Graphical analysis for FVG. Actual births and projection from 1989-2000 trend

\section{Births}

Women with low education and 2+ children

\begin{tabular}{llrrr|r}
\hline Variable & \multicolumn{1}{c}{ Coeff. } & \multicolumn{1}{c}{ s.e. } & \multicolumn{1}{c}{$\mathrm{t}$} & $\mathrm{P}>$ & $\mathrm{t}$ \\
\hline Trend & -21.2554 & 2.2196 & -9.58 & 0.000 \\
Dummy before/after 2000 & 77.9902 & 23.8646 & 3.27 & 0.006 \\
Constant & 471.7337 & 16.4610 & 28.66 & 0.000 \\
\hline
\end{tabular}

R-squared $=0.9097$

$\mathrm{F}(2,14)=70.54$

Prob $>F=0.0000$

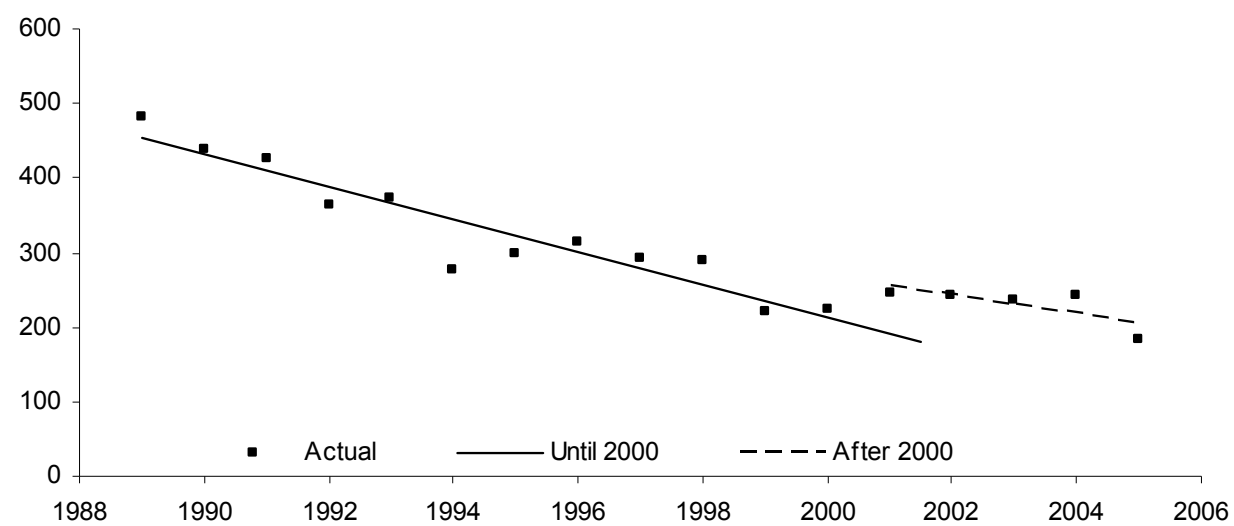

Women with high education and 2+ children

\begin{tabular}{lrrrr|r}
\hline Variable & \multicolumn{1}{c}{ Coeff. } & \multicolumn{1}{c}{ s.e. } & \multicolumn{1}{c}{$\mathrm{t}$} & $\mathrm{P}>$ & $\mathrm{t}$ \\
\hline Trend & 4.8371 & 1.6068 & 3.03 & 0.009 \\
Dummy before/after 2000 & 35.7765 & 17.2762 & 2.07 & 0.057 \\
Constant & 266.8349 & 11.9166 & 22.39 & 0.000 \\
\hline
\end{tabular}

R-squared $=0.8168$

$\mathrm{F}(2,14)=31.22$

Prob $>F=0.0000$

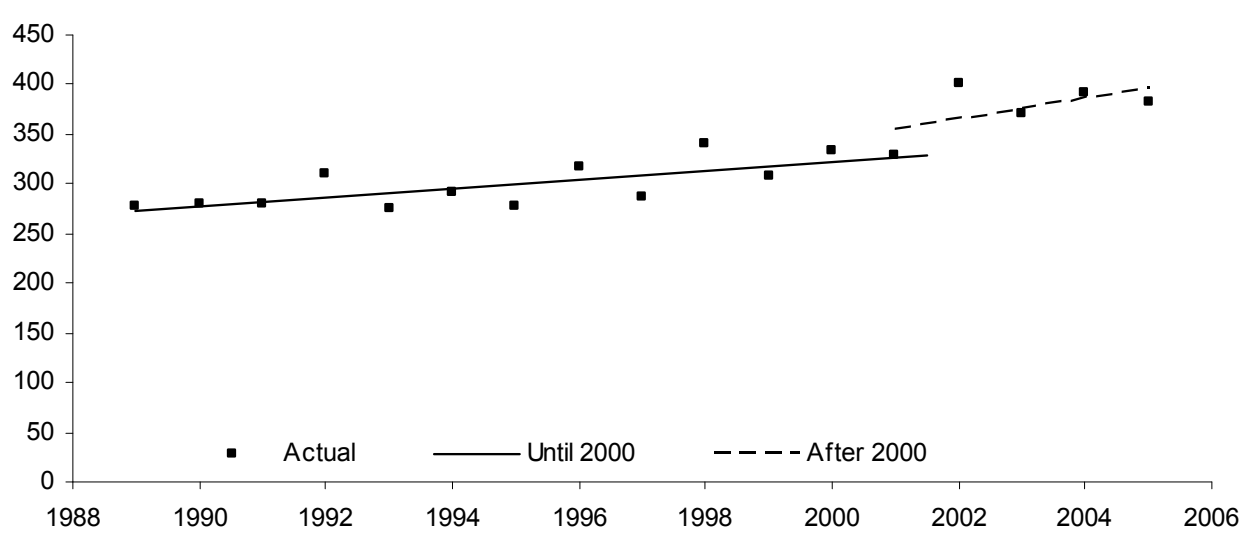


Births (continued)

Women with low education and 1 child

\begin{tabular}{lrrrr}
\hline Variable & \multicolumn{1}{c}{ Coeff. } & \multicolumn{1}{c}{ s.e. } & \multicolumn{1}{c}{$\mathrm{t}$} & $\mathrm{P}>$ \\
\hline Trend & -57.3300 & 3.4943 & -16.41 & 0.000 \\
Dummy before/after 2000 & 22.0564 & 37.5696 & 0.59 & 0.567 \\
Constant & 1725.8776 & 25.9143 & 66.60 & 0.000 \\
\hline R-squ
\end{tabular}

R-squared $=0.9798$

$\mathrm{F}(2,14)=339.06$

Prob $>F=0.0000$

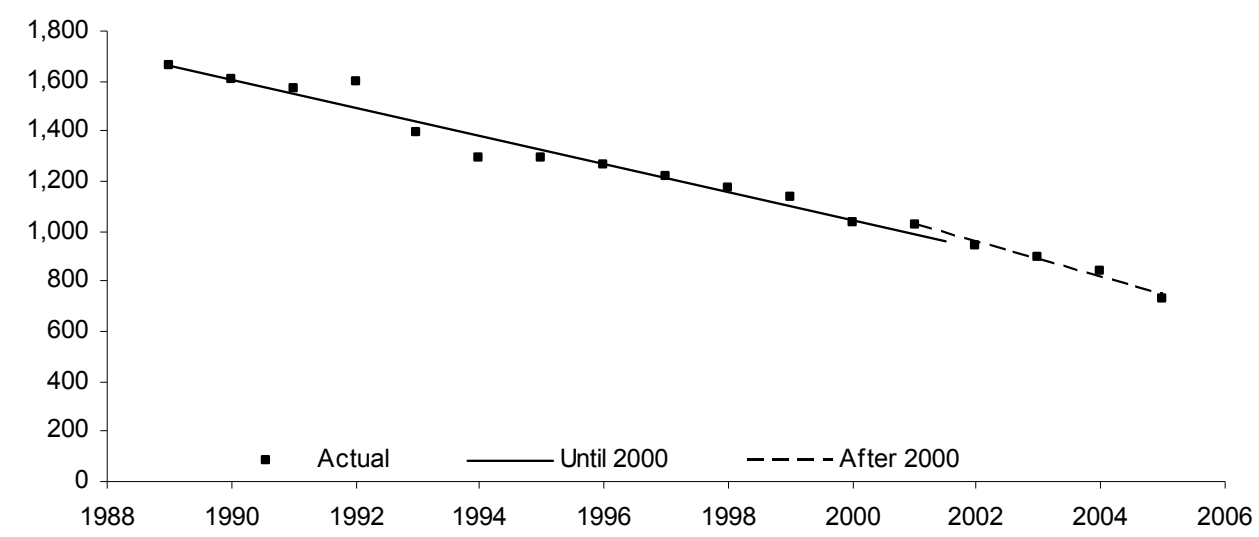

Women with low education and no children

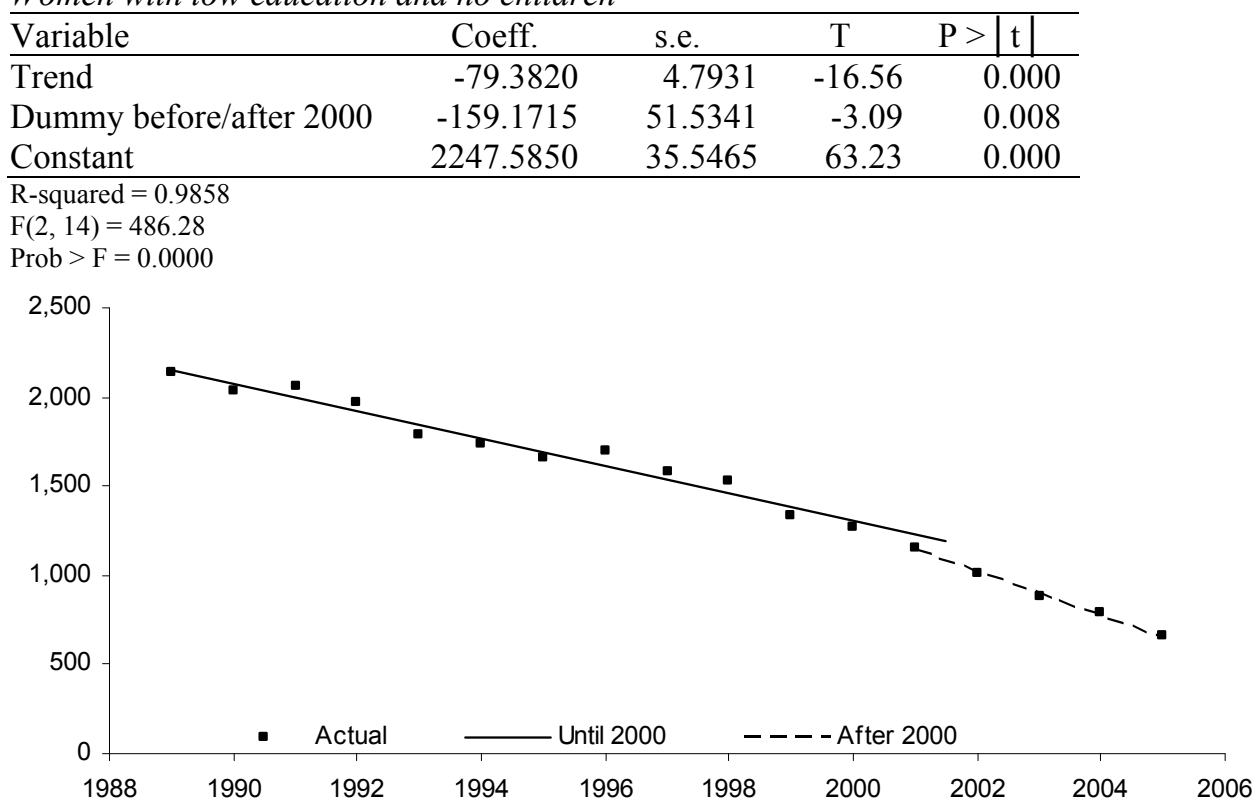




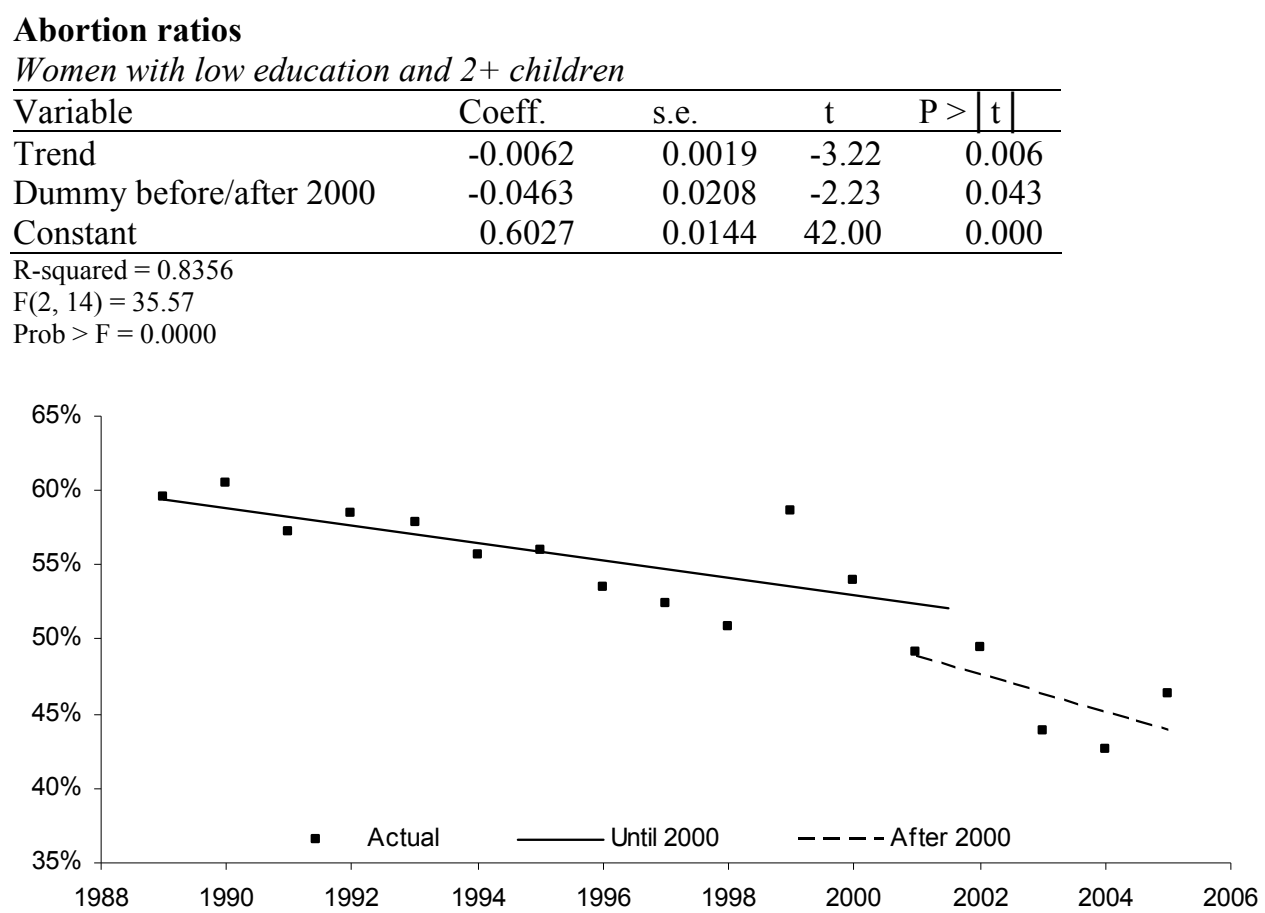

Women with high education and 2+ children

\begin{tabular}{|c|c|c|c|c|}
\hline Variable & Coeff. & s.e. & $\mathrm{t}$ & $\mathrm{P}>\mathrm{t} \mid$ \\
\hline Trend & -0.0069 & 0.0020 & -3.17 & 0.007 \\
\hline Dummy before/after 2000 & -0.0214 & 0.0213 & -1.01 & 0.332 \\
\hline Constant & 0.4251 & 0.0147 & 28.95 & 0.000 \\
\hline
\end{tabular}

R-squared $=0.7542$

$\mathrm{F}(2,14)=21.48$

Prob $>F=0.0001$

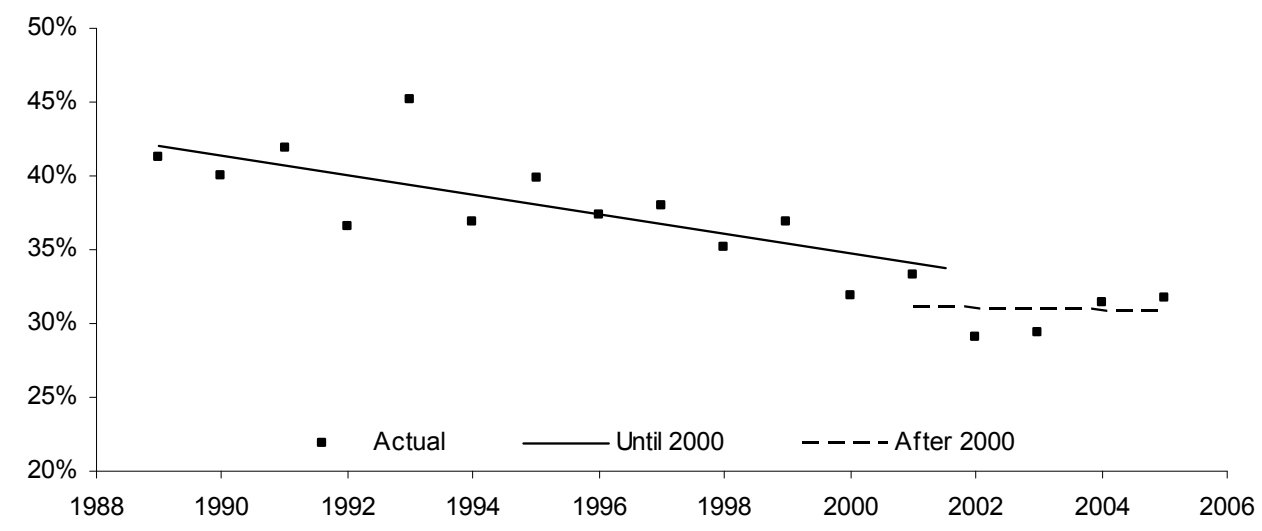




\section{Abortion ratios (continued)}

Women with low education and 1 child

\begin{tabular}{llllr}
\hline Variable & Coeff. & s.e. & $\mathrm{t}$ & $\mathrm{P}>|\mathrm{t}|$ \\
\hline Trend & -0.0054 & 0.0010 & -5.53 & 0.000 \\
Dummy before/after 2000 & -0.0113 & 0.0106 & -1.07 & 0.303 \\
Constant & 0.1871 & 0.0073 & 25.61 & 0.000 \\
\hline R
\end{tabular}

R-squared $=0.8865$

$\mathrm{F}(2,14)=54.70$

Prob $>F=0.0000$

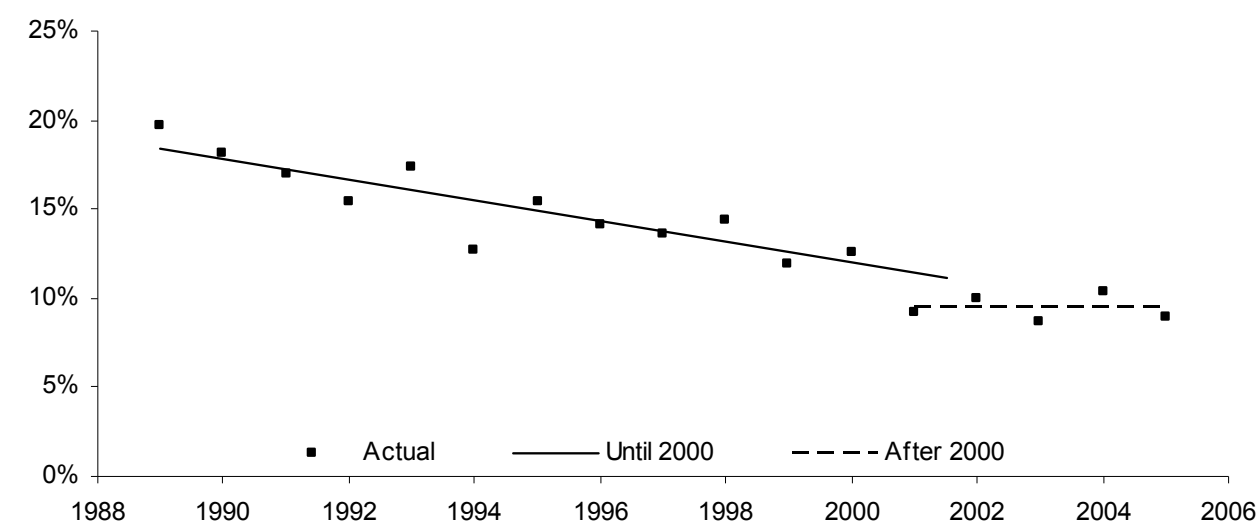

Women with low education and no children

\begin{tabular}{lcccc}
\hline Variable & Coeff. & s.e. & \multicolumn{1}{c}{$\mathrm{t}$} & $\mathrm{P}>|\mathrm{t}|$ \\
\hline Trend & -0.0000 & 0.0005 & -5.53 & 0.987 \\
Dummy before/after 2000 & 0.0076 & 0.0054 & -1.07 & 0.180 \\
Constant & 0.0294 & 0.0037 & 25.61 & 0.000 \\
\hline
\end{tabular}

R-squared $=0.2712$

$\mathrm{F}(2,14)=2.60$

Prob $>F=0.1092$

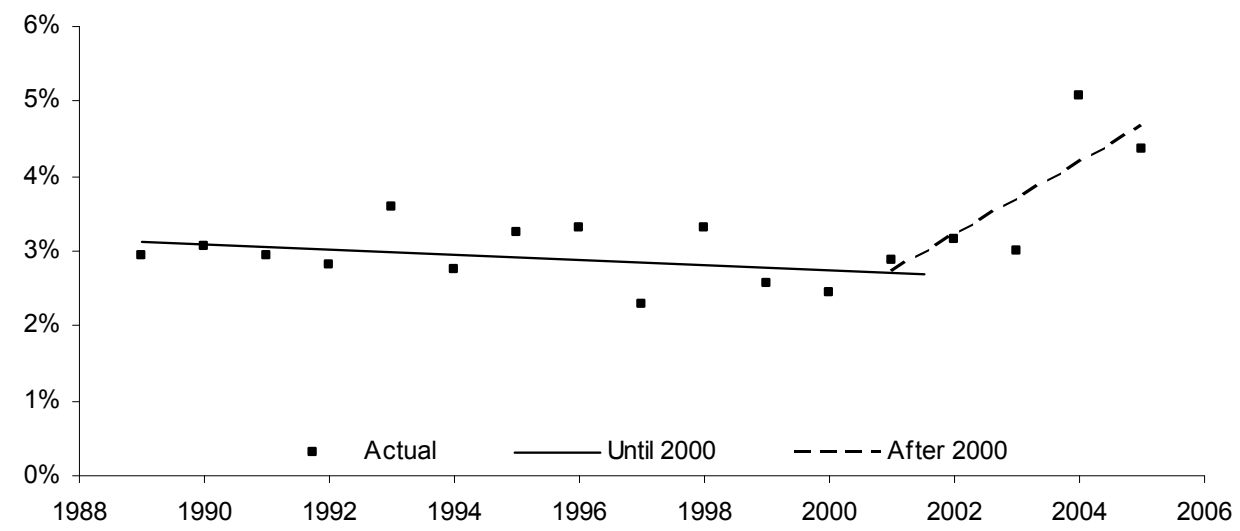


Figure 3:

Index numbers of births $(1989=100)$. Married Italian women living/not living in FVG. Actual births and projection from 1989-2000 trend.

Low educated women

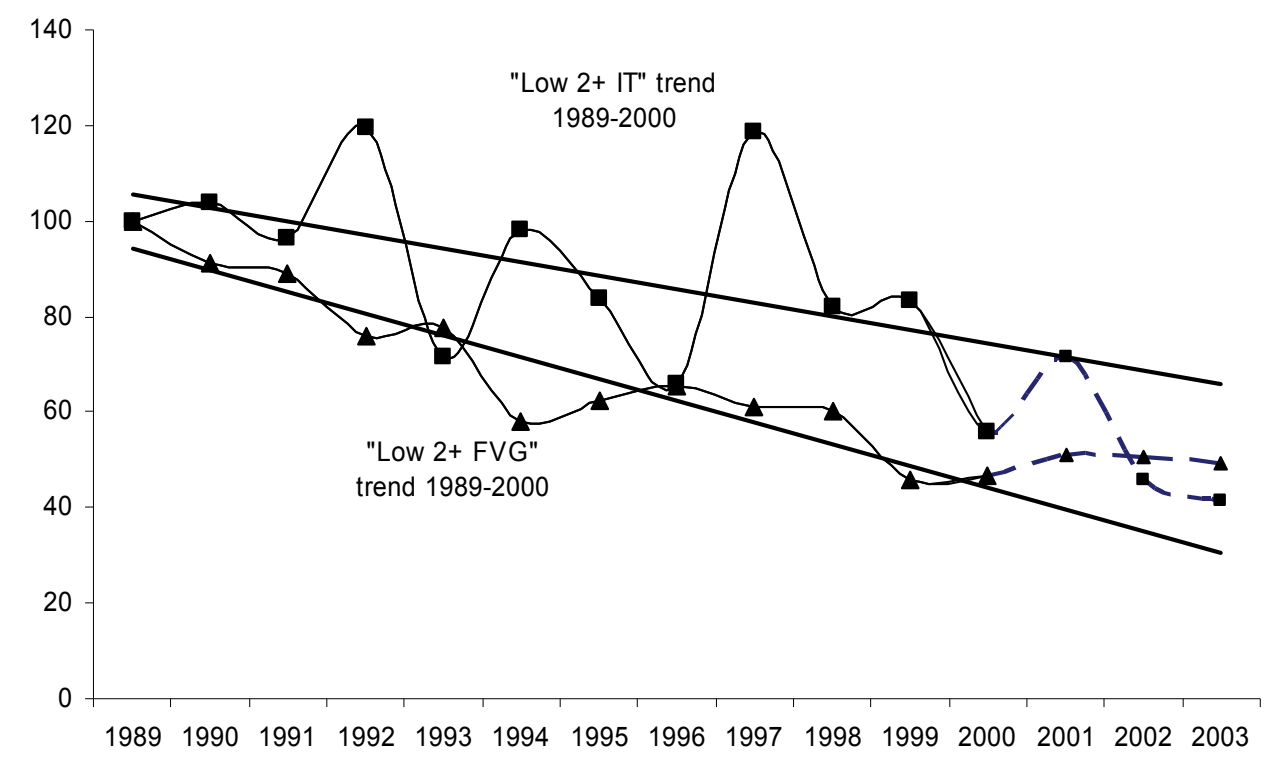

High educated women

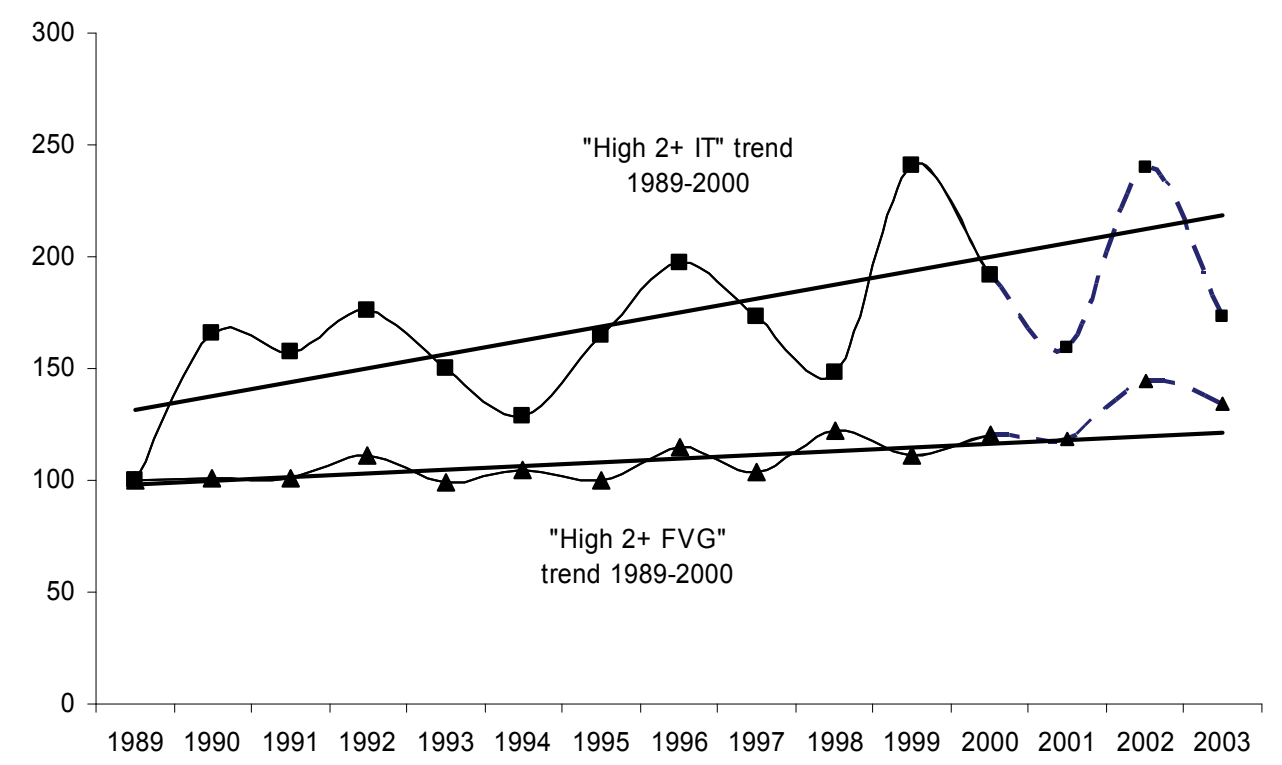




\subsection{Multivariate analysis}

We focus our analysis on the interactions between time, marital status, parity, and education (or citizenship): $\lambda_{i j k m}^{X Y Z T}$ and $\lambda_{i j h m}^{X Y W T}$. Both are statistically significant, and when omitted from the model cause a noticeable drop in the goodness-of-fit $(p<0.01)$. Figure 4 shows the outcome of these interactions by parity in 2000 and in 2001-03, for married women who were citizens of the EU (a) and married loweducated women (b). The higher the interaction, the higher the number of corresponding births: during 2001-03 the direction of the interactions with parity drastically changed, favouring births among women with two or more children. As hypothesised in Section 3.2, we observe $\lambda_{3114}^{X Y Z T}<\lambda_{4114}^{X Y Z T}$ (less-educated married women of high parity had more children in 2001-03 than in 2000) and $\lambda_{3114}^{X Y W T}<$ $\lambda_{4114}^{X Y W T}$ (married women of high parity and with EU citizenship had more children during 2001-03 than in 2000). With regard to the logistic model of induced abortion, the results (not shown here, available on request) do not conflict with our expectations, although a clear change in the sign of the parameters is not present when moving from low to high parities, as observed in the log-linear model for births.

\section{Figure 4:}

Log-linear model on births: interaction of time, parity, marital status, citizenship and education in FVG

\section{(a) Married women, citizens of European Union}

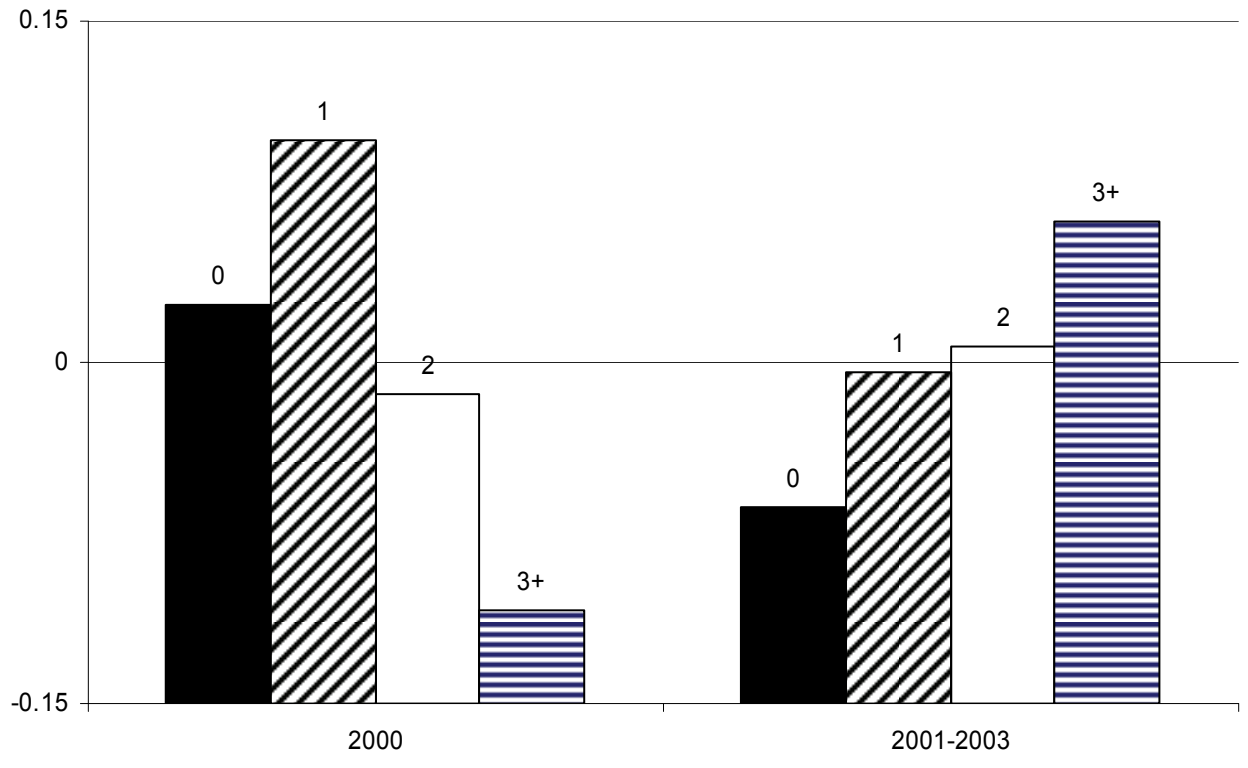




\section{(b) Married low educated women}

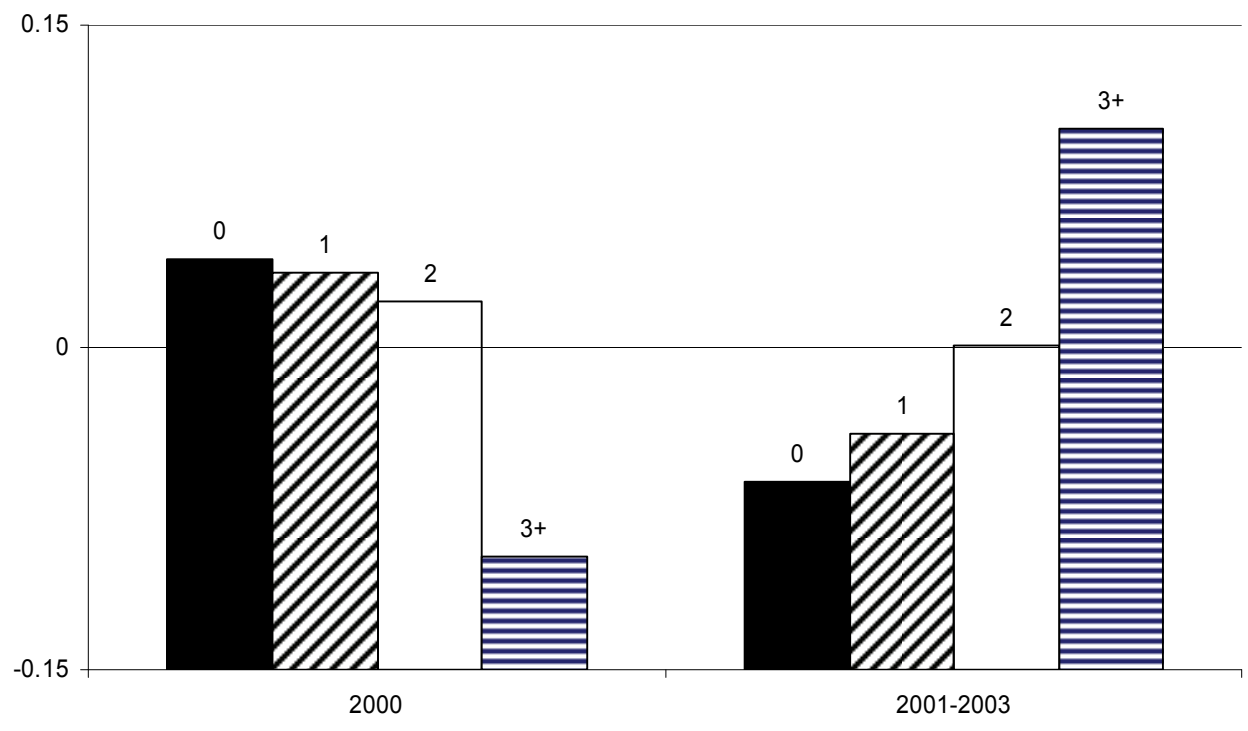

Note: The components of each interaction sum to zero

\section{Conclusions}

In this paper we studied the case of the northern Italian region of Friuli-Venezia Giulia, where a fertility policy offering considerable monetary bonus at birth was implemented in the years 2000-2003. We analysed the differences between the observed number of births and abortion ratios in years 2001-2004 and projected births and abortions ratios based on the assumption of the previous (1989-2000) trend remaining unchanged. We found noteworthy differences between women hypothetically non-eligible and eligible for the bonus at birth, especially for those with two or more children and low education. This result is strengthened by the fact that in other regions of Italy-where no monetary measures were implemented in addition to those already adopted at the national level-we observe no significant variation in birth trends for the same period and the same groups of women.

We can thus confirm - albeit within the limits of this study - that the bonus may have contributed to increasing higher-order births in FVG, particularly for women with low levels of education who already had at least two children. As the number of these women is relatively low, the estimated effect on total fertility was modest. Our analysis indicates that around 1,000 more births than expected by trend extrapolation took place in the four-year period of 2001-2004, which represents an increase of $2-3 \%$ in total births (but about $20 \%$ or more in births of birth order 3 and higher). 
This pattern could be explained by a tempo effect. In other words, the bonus may have simply accelerated the birth of a planned child (leading to a change in birth timing rather than inducing a permanent effect of the bonus on fertility). Further investigation will only become feasible, however, when it will be possible to compare, at the end of their reproductive lives, the completed fertility of these cohorts. However, our results indicate that the abortion ratio of low educated women with two or more children has also been influenced by the bonus. This may be interpreted as a sign of the effect of the bonus on the quantum of births, as these women used abortion to limit rather than postpone fertility.

The importance of our results is further highlighted by comparable results for Italy obtained by Billari et al. (2005), who studied the effects of monetary aid provided to families with three or more children (introduced by the Turco law of 1999). Over the last thirty years, both Italy and FVG have been characterised by a large gap between desired and actual fertility and this discrepancy is particularly marked for poorer couples.

This is not to say that the best way to help Italian couples who would like more children is to generalise the bonus-at-birth program. The motives behind having a child or not are quite complex and diverse. Economic reasons, in all probability, are important only for poorer couples who already have one or two children. Moreover, in the survey mentioned in the introduction, women suggested that substantive monetary transfers over the first three years after the birth of a child would have convinced them to have a second or third child (De Santis and Breschi 2003). Continuous monetary aid over time is thus seen more favourably than a substantial one-time bonus at birth. More generally, a reduction in the direct costs of childrearing may be effective in raising fertility among lowincome Italian women, freeing them from the constraints associated with limited economic resources.

\section{References}

Angrist, J. D. and A. B. Krueger. 1999. "Empirical strategies in labor economics." In: O. C. Ashenfelter and D. Card (eds.) Handbook of Labor Economics. Amsterdam, NorthHolland, Vol. 3, Chapter 23.

Bettio, F. and P. Villa. 1998. "A Mediterranean perspective on the breakdown of the relationship between job participation and fertility." Cambridge Journal of Economy 22: 137-171.

Billari, F. C., G. Dalla Zuanna, and M. Loghi. 2005. "Assessing the impact of family friendly monetary transfers in a lowest-low fertility setting." Paper presented at the Annual Meeting of the Population Association of America, Philadelphia, April 2005.

Boccuzzo, G., M. Caltabiano, G. Dalla Zuanna, and M. Loghi. 2008. "When money matters. The impact of the bonus at birth on reproductive behaviour in a lowest-low fertility context: Friuli-Venezia Giulia (Italy) from 1989 to 2005." WP 8/08, Dept. of Statistical Sciences, University of Padua, Italy, «http://www.stat.unipd.it/ricerca/wp». 
Dalla Zuanna, G. 2001. "The banquet of Aeolus: a familistic interpretation of Italy's lowest low fertility." Demographic Research 4(5): 133-162.

Dalla Zuanna, G. and A. Righi. 1999. Nascere nelle cento Italie. ISTAT, Coll. Argomenti, 18, Roma.

De Santis, G. and M. Breschi. 2003. "Fecondità, costrizioni economiche e interventi politici." In: M. Breschi and M. Livi Bacci (eds.) La bassa fecondità italiana tra costrizioni economiche e cambio di valori. Presentazione delle indagini e risultati. Udine: Forum, pp. 189-210.

Fauveau, V. 1994. "Data collection system and datasets available in Matlab." In: V. Fauveau (ed.) Matlab: Women, Children and Health. Dhaka, Bangladesh, ICDDR,B.

Gauthier, A. H. 2004. "Choices, opportunities and constraints on partnership, childbearing and parenting: the policy responses." Background paper for the session on: Childbearing and parenting in low fertility countries: Enabling choices. European Population Forum, Geneva, United Nations.

Gauthier, A. H. 2007. "The impact of family policies on fertility in industrialized countries: a review of the literature." Population Research and Policy Review 26(3): 323-346.

Istat - Italian National Statistical Institute. 2006. Natalità e fecondità della popolazione residente: caratteristiche e tendenze recenti. Rome. Available online «Www.istat.it/salastampa/comunicati/non_calendario/20060801_00/testointegrale.pdf».

Kalwij, A. 2008. "The Impact of Family Policy Expenditure on Fertility in Western Europe." Paper presented at the ESPE Conference of London (19-21 June), Online «http://espe.conference-services.net/viewPDF.asp?conferenceID=1190\&abstractID=198240».

Livi Bacci, M. 2001. "Too few children and too much family." Daedalus 3: 139-156.

McDonald, P. 2000. "Gender equity in theory of fertility transition." Population and Development Review 26: 427-439.

Mills, M., L. Mencarini, M. L. Tanturri, and K. Begall. 2008. "Gender equity and fertility intentions in Italy and the Netherlands." Demographic Research 18(1); «http://www.demographic-research.org/Volumes/Vol18/1/».

OECD 2004. Education at a Glance. Paris.

Salvini, S. 2004. "Low Italian Fertility: the Bonaccia of Antilles?" Genus 60(1): 19-38.

Samara, R., B. Buckner, and A. Ong Tsui. 1996. Understanding How Family Planning Programs Work: Findings from Five Years of Evaluation Research. Chapel Hill: N.C.: EVAlUATION Project, Carolina Population Center, University of North Carolina. 


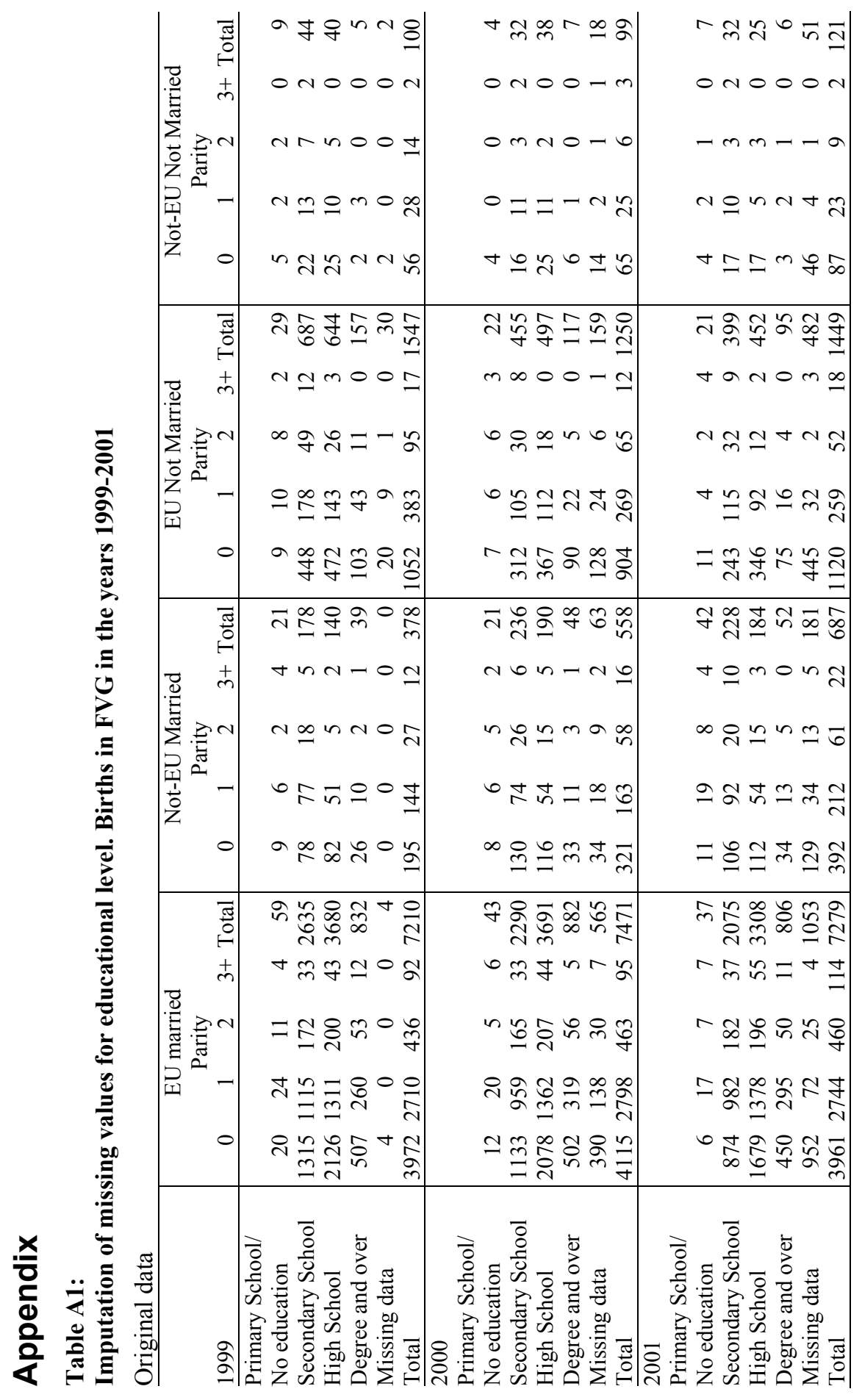




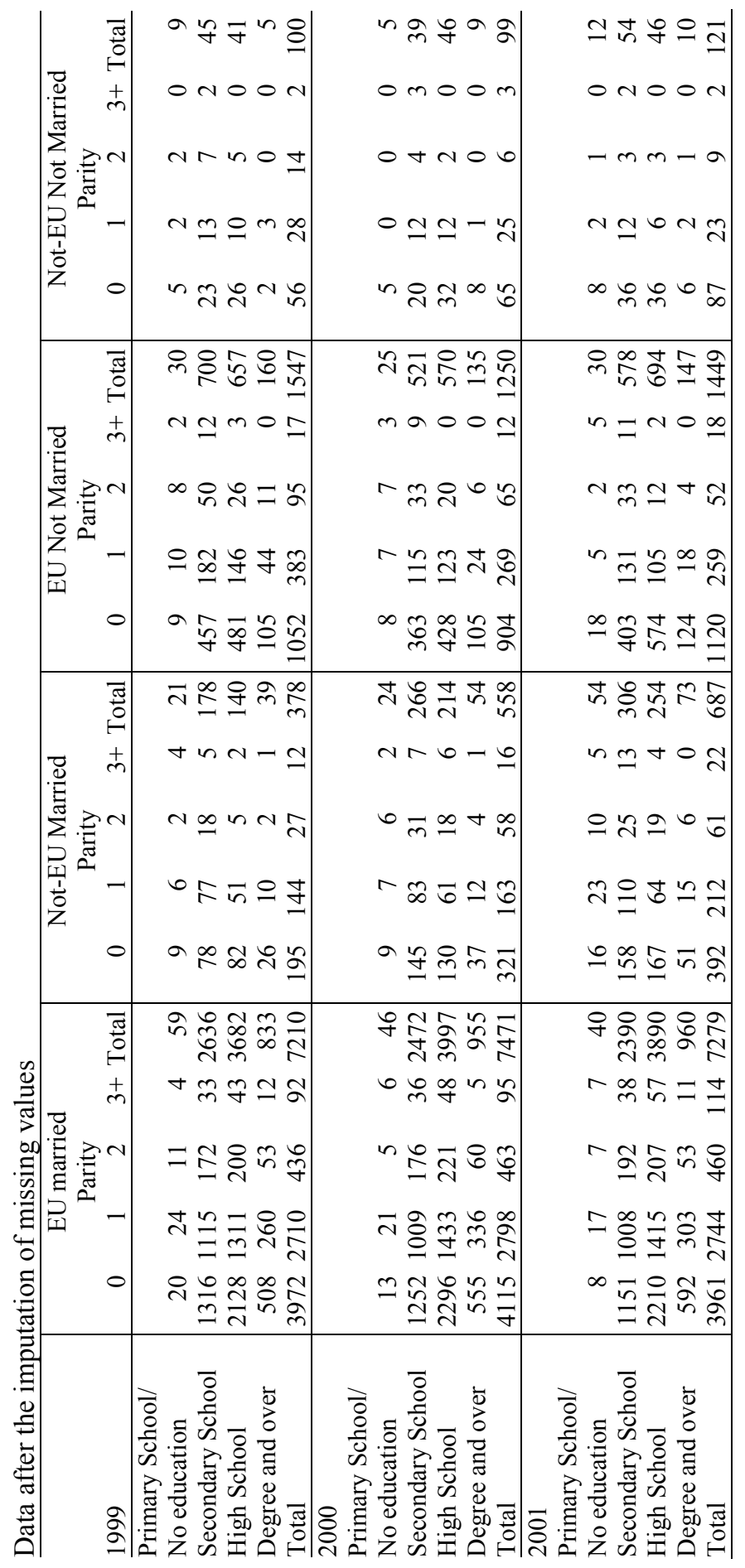

